\title{
Effects of Temperature and Stirring on
} Mass Transfer to Maximize Biodiesel Production from Jatropha curcas Oil: A Mathematical Study

\author{
Fahad Al Basir and Priti Kumar Roy \\ Centre for Mathematical Biology and Ecology, Department of Mathematics, Jadavpur University, Kolkata 700032, India \\ Correspondence should be addressed to Priti Kumar Roy; pritiju@gmail.com
}

Received 8 May 2015; Revised 29 September 2015; Accepted 12 October 2015

Academic Editor: Viktor Popov

Copyright ( 2015 F. Al Basir and P. K. Roy. This is an open access article distributed under the Creative Commons Attribution License, which permits unrestricted use, distribution, and reproduction in any medium, provided the original work is properly cited.

\begin{abstract}
Biodiesel, the most promising renewable and alternative energy, is produced through transesterification of vegetable oils. One of the most cost effective sources of biodiesel is Jatropha curcas oil. Transesterification of Jatropha oil depends significantly on reaction parameters such as reaction time, temperature, molar ratio, catalyst amount, and stirrer speed. Among these parameters temperature and stirring have noteworthy effect on mass transfer. In this research article, we have shown the simultaneous effect of temperature and stirring on mass transfer by considering a mathematical model. The optimal profiles of temperature and stirring are determined as a combined parameter, for which maximum biodiesel can be obtained. Further, we have shown that this pair exists and is unique for the optimality of the system.
\end{abstract}

\section{Introduction}

Esters of vegetable oils are known as biodiesel and used as an alternative fuel for diesel [1]. Biodiesel is a nonpolluting, locally available, accessible, sustainable, and reliable fuel obtained from renewable sources such as vegetable oils or animal fats by transesterification [2]. An alternative way of biodiesel synthesis is produced from vegetable oils. Jatropha oil is one of such nonedible oils, which has an estimated annual production potential of 200 thousand metric tons in India and it contains high amount of oil, that is, triglycerides, and the produced biodiesel has a similar property as that of diesel [3].

Transesterification or alcoholysis is adopted to convert Jatropha curcas oil, to biodiesel. Two types of transesterification have been developed and analysed for biodiesel production using either chemical catalyst or biological catalyst [4-7]. There are ample research articles where alkaline transesterification for biodiesel production is investigated [8-10]. Raw materials with a high water or free fatty acid content need pretreatment with an acidic catalyst in order to esterify FFA [11, 12]. It is evident that reaction parameters such as molar ratio between alcohol and oil, reaction time, catalyst concentration, and reaction temperature influenced the transesterification process [13-15].

Triglycerides are immiscible with alcohol due to polar and nonpolar nature of alcohol and oil, respectively. Thus, biodiesel production process suffers initial mass transfer limitations problem [16]. This problem can be avoided by applying stirring on the system. Roy et al. [4, 17] successfully observed the effect of stirring on transesterification by formulating a mathematical model. Noureddini and Zhu proposed an initial mass transfer controlled region followed by a kinetically controlled region for base catalytic transesterification of sunflower oil [18]. Hou et al. showed that the reaction is very slow initially due to mass transfer limitations between methanol and oil phase [19]. Peterson et al. [20] have studied the effect of stirrer speed on the transesterification of vegetable oil with alcohol. Rashid et al. also observed the stirring intensity of the transesterification of cotton seed oil using several catalyst under experimental setup and analytical chemistry of fuel properties [21]. Sharma et al. have observed that beyond an optimum stirrer speed production level decreases [22]. 
In a previous study, influence of temperature on mass transfer is investigated in case of biodiesel production from Jatropha curcas oil [23]. It is observed that, with an increase in reaction temperature, conversion of oil increased significantly; that is, mass transfer has been increased [5, 12, 24]. But after a certain level of temperature $\left(50^{\circ} \mathrm{C}\right)$, biodiesel yield decreases $[25,26]$. It was shown by many researchers that mass transfer is highly dependent on temperature. At fixed stirring, mass transfer rate is directly proportional to its temperature profile, that is, high mass transfer at high temperature $[6,27]$.

Hence, mass transfer limitation is one of the most deciding factors for optimum production of biodiesel. Optimization of mechanical agitation and temperature for the evaluation of the mass transfer resistance is essential in transesterification of Jatropha oil. In this research article, we have considered a mathematical model [17] for biodiesel production and unveil the combined effect of temperature and stirring on mass transfer in different phases of biodiesel production. Using mathematical control theory, optimal profiles for temperature and stirring are derived. Our aim is to minimize mass transfer limitation to get maximum biodiesel production and make the process cost effective. We have also shown the existence and uniqueness of control variables for the optimal system. Analytical results are shown numerically using Matlab.

\section{The Mathematical Model}

In this research article, we have attenuated two key parameters of our model system, which has been studied in detail in our previous works $[17,23]$. We have chosen temperature and stirring as a combined parameter and study the dynamical behaviour impacted on biodiesel production due to different stirring as well as fluctuations of reaction temperature. The base model is constructed from the previous works [17, 23 ] and here we assume the same reaction mechanism as described in previous work. For a detailed discussion of the model assumptions one may refer to our earlier works [17, 23].

Biodiesel (BD) can be produced by reacting Jatropha oil (i.e., triglycerides $(\mathrm{TG})$ ) with methanol $(\mathrm{AL})$. The reactions happen in three consecutive reversible steps. During the course of reaction of triglycerides and methanol, some intermediates (diglyceride (DG) and monoglyceride (MG)) are formed. The schematic explanation of the reaction is given by

$$
\begin{aligned}
& \mathrm{TG}+\mathrm{AL} \underset{k_{2}}{\stackrel{k_{1}}{\rightleftharpoons}} \mathrm{DG}+\mathrm{BD}, \\
& \mathrm{DG}+\mathrm{AL} \underset{k_{4}}{\stackrel{k_{3}}{\rightleftharpoons}} \mathrm{MG}+\mathrm{BD}, \\
& \mathrm{MG}+\mathrm{AL} \underset{k_{6}}{\stackrel{k_{5}}{\rightleftharpoons}} \mathrm{GL}+\mathrm{BD} .
\end{aligned}
$$

We denote the concentration of biodiesel, triglycerides, diglycerides, monoglycerides, methanol (alcohol), and glycerol by $x_{B}, x_{T}, x_{D}, x_{M}, x_{A}$, and $x_{G}$, respectively. We have the following set of rate equations as described in [17, 23]:

$$
\begin{aligned}
& \frac{d x_{B}}{d t}=k_{1} x_{T} x_{A}-k_{2} x_{D} x_{B}+k_{3} x_{D} x_{A}-k_{4} x_{M} x_{B} \\
& +k_{5} x_{M} x_{A}-k_{6} x_{G} x_{B}+k_{S} x_{B}\left(1-\frac{x_{B}}{B_{\max }}\right), \\
& \frac{d x_{T}}{d t}=-k_{1} x_{T} x_{A}+k_{2} x_{D} x_{B} \\
& \frac{d x_{D}}{d t}=k_{1} x_{T} x_{A}-k_{2} x_{D} x_{B}-k_{3} x_{D} x_{A}+k_{4} x_{M} x_{B}, \\
& \frac{d x_{M}}{d t}=k_{3} x_{D} x_{A}-k_{4} x_{M} x_{B}-k_{5} x_{M} x_{A}+k_{6} x_{G} x_{B}, \\
& \frac{d x_{A}}{d t}=-k_{1} x_{T} x_{A}+k_{2} x_{D} x_{B}-k_{3} x_{D} x_{A}+k_{4} x_{M} x_{B} \\
& -k_{5} x_{M} x_{A}+k_{6} x_{G} x_{B} \\
& \frac{d x_{G}}{d t}=k_{5} x_{M} x_{A}-k_{6} x_{G} x_{B} \text {, }
\end{aligned}
$$

with initial conditions,

$$
\begin{aligned}
& x_{B}(0)=0, \\
& x_{T}(0)=x_{T_{0}}, \\
& x_{D}(0)=0, \\
& x_{M}(0)=0, \\
& x_{A}(0)=x_{A_{0}}, \\
& x_{G}(0)=0 .
\end{aligned}
$$

Here, $k_{1}, k_{3}$, and $k_{5}$ are forward and $k_{2}, k_{4}$, and $k_{6}$ are backward reaction rates. The dependency of reaction rate constants on the temperature, $k_{i}(i=1$ to 6$)$, is expressed by the Arrhenius equation [26]:

$$
k_{i}=\alpha_{i} e^{-\beta_{i} / T} .
$$

$T$ is the reaction temperature, $\alpha_{i}$ is the frequency factor, and

$$
\beta_{i}=\frac{E \alpha_{i}}{R}
$$

in which $E \alpha_{i}$ is the activation energy for each component and $R$ is the universal gas constant. Using the values of $\alpha_{i}$ and $\beta_{i}$ [26], we obtain the values of $k_{i}$. T is the reaction temperature, $\alpha_{i}$ and $\beta_{i}$ are constants, and their values are given in Table 1. We use $k_{s}$ as the mass transfer rate constant due to stirring and it is defined as $[17,23]$

$$
k_{s}=\frac{a}{1+\exp (-b(N-c))},
$$

where $N$ is the speed of stirrer and $a, b$, and $c$ are constants. The term $k_{s}$ is used in our model by the expression 
TABLE 1: Values of parameters used in numerical calculation at temperature $50^{\circ} \mathrm{C}[18,26]$.

\begin{tabular}{lc}
\hline Parameters & Value \\
\hline$\alpha_{1}$ & $3.92 e 7$ \\
$\alpha_{2}$ & $5.77 e 5$ \\
$\alpha_{3}$ & $5.88 e 12$ \\
$\alpha_{4}$ & $0.098 e 10$ \\
$\alpha_{5}$ & $5.35 e 3$ \\
$\alpha_{6}$ & $2.15 e 4$ \\
\hline$\beta_{1}$ & 6614.83 \\
$\beta_{2}$ & 4997.98 \\
$\beta_{3}$ & 9993.96 \\
$\beta_{4}$ & 7366.64 \\
$\beta_{5}$ & 3231.18 \\
$\beta_{6}$ & 4824.87 \\
\hline
\end{tabular}

$k_{s} x_{B}\left(1-x_{B} / B_{\max }\right)$. Here, $B_{\max }$ represents maximum biodiesel production in an ideal situation, which is defined as a system having no mass transfer resistance.

\section{Boundedness of the System}

The right hand side of (2) is smooth functions of the variables $x_{T}, x_{B}, x_{A}, x_{G}, x_{D}$, and $x_{M}$ and system parameters; as long as these quantities are nonnegative, the local existence, uniqueness, and continuous properties hold. In the next theorem we show that the solution of the system is bounded.

Theorem 1. The solution $x(t)$ of (2), where $x=$ $\left(x_{B}, x_{T}, x_{D}, x_{M}, x_{A}, x_{G}\right)$, is uniformly bounded.

Proof. We define the function $W(t): R_{0},_{+} \rightarrow R_{0}$, by

$$
W(t)=x_{B}+x_{T}+x_{D}+x_{M}+x_{A}+x_{G} .
$$

Observe that $W$ is well-defined and differentiable on some maximal interval $\left(0, t_{f}\right)$.

The derivative of (7) is

$$
\begin{gathered}
\frac{d W(t)}{d t}=\sum \frac{d x_{i}}{d t}, \\
\frac{d W(t)}{d t}+W(t)=k_{S} x_{B}\left(1-\frac{x_{B}}{B_{\max }}\right) \leq k_{S} x_{B}, \\
\quad \text { since } B_{\max }>x_{B} \forall t, \\
\frac{d W(t)}{d t}+W(t) \leq k_{S} B_{\max }=k \text { say, for each } t \in\left(0, t_{f}\right) .
\end{gathered}
$$

Using Gronwall's inequality (differential form) [28], we can write

$$
W(t) \leq k-(k-W(0)) e^{-t} .
$$

Thus $W(t)$ is bounded on $\left(0, t_{f}\right)$. Now, suppose $t_{f}<\infty$; then $W\left(t_{f}\right)<\infty$. Thus solutions of the systems are uniformly bounded.

\section{The Optimal Control Problem}

Optimal control is a useful mathematical tool for controlling a chemical system like biodiesel production. Generally, we use these types of method towards a system by finding the time dependent profiles of the control variables to optimize a particular performance. Here, we use the control pair $u^{*}(t)=$ $\left(u_{1}(t), u_{2}(t)\right)$, which represents the stirring activator input and temperature input, respectively, at time $t$ satisfying $0 \leq$ $u_{i}(t) \leq 1, i=1,2$ [29]. Also, $u_{i}(t)=1$ represents the maximal use of control and $u(t) \approx 0$ signifies no use of control.

Based on the above assumptions, system (2) would be

$$
\begin{aligned}
\frac{d x_{B}}{d t}= & k_{1} u_{1}(t) x_{T} x_{A}-u_{1}(t) k_{2} x_{D} x_{B} \\
& +u_{1}(t) k_{3} x_{D} x_{A}-u_{1}(t) k_{4} x_{M} x_{B} \\
& +u_{1}(t) k_{5} x_{M} x_{A}-u_{1}(t) k_{6} x_{G} x_{B} \\
& +u_{2}(t) k_{S} x_{B}\left(1-\frac{x_{B}}{B_{\max }}\right), \\
\frac{d x_{T}}{d t}= & -u_{1}(t) k_{1} x_{T} x_{A}+u_{1}(t) k_{2} x_{D} x_{B}, \\
\frac{d x_{D}}{d t}= & u_{1}(t) k_{1} x_{T} x_{A}-u_{1}(t) k_{2} x_{D} x_{B} \\
& -u_{1}(t) k_{3} x_{D} x_{A}+u_{1}(t) k_{4} x_{M} x_{B}, \\
\frac{d x_{M}}{d t}= & u_{1}(t) k_{3} x_{D} x_{A}-u_{1}(t) k_{4} x_{M} x_{B} \\
& -u_{1}(t) k_{5} x_{M} x_{A}+u_{1}(t) k_{6} x_{G} x_{B}, \\
\frac{d x_{A}}{d t}= & -u_{1}(t) k_{1} x_{T} x_{A}+u_{1}(t) k_{2} x_{D} x_{B} \\
& -u_{1}(t) k_{3} x_{D} x_{A}+u_{1}(t) k_{4} x_{M} x_{B} \\
& -u_{1}(t) k_{5} x_{M} x_{A}+u_{1}(t) k_{6} x_{G} x_{B}, \\
\frac{d x_{G}}{d t}= & u_{1}(t) k_{5} x_{M} x_{A}-u_{1}(t) k_{6} x_{G} x_{B} .
\end{aligned}
$$

Initial conditions of the system (11) are $x_{B}(0)=0, x_{T}(0)=$ $x_{T_{0}}, x_{D}(0)=0, x_{M}(0)=0, x_{A}(0)=x_{A_{0}}$, and $x_{G}(0)=0$. Here $B_{\max }$ is the maximum $\mathrm{BD}$ production which can be obtained in an ideal reaction condition and $k_{S}$ is the mass transfer rate constant.

The system (10) can be written in compact form as

$$
\frac{d x_{i}}{d t}=f_{i}\left(x, u_{1}, u_{2}, t\right)
$$

where $f_{i}(i=1, \ldots, 6)$ are the right sides of system (10) and $x_{i}(i=1, \ldots, 6)$ are the state variables representing the concentration of each of the components $x_{B}, x_{T}, x_{D}, x_{M}, x_{A}$, and $x_{G}$, respectively. 
We want to maximize the biodiesel concentration and minimize the cost of production. The objective functional is thus formulated as

$$
J[u(t)]=\int_{t_{i}}^{t_{f}}\left[P u_{1}^{2}(t)+Q u_{2}^{2}(t)-R x_{B}^{2}(t)\right] d t .
$$

The parameters $P>0, Q>0$ are the weight constants on the benefit of the cost of production and $R>0$ is the penalty multiplier. Now, the objective is to find the optimal control pair $u^{*}(t)=\left(u_{1}(t), u_{2}(t)\right)$ such that

$$
\begin{aligned}
& J\left(u_{1}^{*}, u_{2}^{*}\right)=\min \left(J\left(u_{1}, u_{2}\right):\left(u_{1}, u_{2}\right) \in U\right), \\
& \quad \text { where } U=U_{1} \times U_{2}, \\
& \begin{aligned}
U_{1} & =\left(u_{1}(t): u_{1} \text { is measurable, } 0 \leq u_{1} \leq 1, t\right. \\
& \left.\in\left[t_{i}, t_{f}\right]\right), \\
U_{2} & =\left(u_{2}(t): u_{2} \text { is measurable, } 0 \leq u_{2} \leq 1, t\right. \\
& \left.\in\left[t_{i}, t_{f}\right]\right) .
\end{aligned}
\end{aligned}
$$

Here Pontryagin Minimum Principle [30] has been used to find the optimal control pair $\left(u_{1}^{*}(t), u_{2}^{*}(t)\right)$.

4.1. Existence of an Optimal Control Pair. The existence of the optimal control pair can be obtained using the result by Fleming and Rishel in [31] and in [32].

Theorem 2. There exists an optimal control pair $\left(u_{1}^{*}, u_{2}^{*}\right) \in U$ such that

$$
J\left(u_{1}^{*}, u_{2}^{*}\right)=\min \left(J\left(u_{1}, u_{2}\right):\left(u_{1}, u_{2}\right) \in U\right) .
$$

Proof. To use the result in [31], we must check the following conditions:

(1) The set of controls and corresponding state variables is nonempty.

(2) The control set $U$ is convex and closed.

(3) The right-hand side of the state system is bounded by a linear function in the state and control variables.

(4) The integrand of the objective functional is concave on $U$.

(5) There exists constants $c_{1}, c_{2}>0$, and $m>1$ such that the integrand $L\left(x, z, u_{1}, u_{2}\right)$ of the objective functional satisfies

$$
L\left(x_{B}, u_{1}, u_{2}\right) \leq c_{2}-c_{1}\left(\left|u_{1}\right|^{2}+\left|u_{2}\right|^{2}\right)^{m / 2} .
$$

In order to verify these conditions, we use a result by Lukes in [32] to give the existence of solutions of system (10) with bounded coefficients, which gives condition (1). We note that the solutions are bounded. Our control set satisfies condition (2). Since our state system is bilinear in $u_{1}, u_{2}$, the right hand side of system (10) satisfies condition (3), using the boundedness of the solutions. Note that the integrand of our objective functional is concave. Also we have the last condition needed,

$$
L\left(x_{B}, u_{1}, u_{2}\right) \leq c_{2}-c_{1}\left(\left|u_{1}\right|^{2}+\left|u_{2}\right|^{2}\right)^{m / 2}
$$

where $c_{2}$ depends on the upper bound on $x_{B}$, and $c_{1}>0$ since $P, Q>0$. We conclude that there exists an optimal control pair for the system (10) for which objective functional, $J\left(u_{1}, u_{2}\right)$, will be minimized.

4.2. The Optimality System. Pontryagin's minimum Principle, given in [31], provides necessary conditions for the optimal control problem. This principle converts (12), (14), and (17) into a problem of minimizing an Hamiltonian. By applying Pontryagin's minimum principle in state, we obtain the following theorem.

Theorem 3. If the given optimal control $u^{*}(t)$ and the solution $\left(x_{B}^{*}, x_{T}^{*}, x_{D}^{*}, x_{M}^{*}, x_{A}^{*}, x_{G}^{*}\right)$ of the corresponding system (10) minimize $J(u)$ over $U$, then there exists the adjoint variables $\xi_{1}$, $\xi_{2}, \xi_{3}, \xi_{4}, \xi_{5}$ and $\xi_{6}$ which satisfying the following equations:

$$
\begin{aligned}
& \frac{d \xi_{1}}{d t}=2 Q x_{B}-\xi_{1}\left\{-u_{1} k_{2} x_{D}-u_{1} k_{4} x_{M}+u_{1} k_{6} x_{G}\right. \\
& \left.-k_{S}\left(1-\frac{2 x_{B}}{B_{\max }}\right)\right\}+\xi_{2} u_{1} k_{2} x_{D}+\xi_{3}\left(-u_{1} k_{2} x_{D}\right. \\
& \left.-u_{1} k_{3} x_{A}+u_{1} k_{4} x_{M}\right)-\xi_{4}\left(-u_{1} k_{4} x_{M}+u_{1} k_{6} x_{G}\right) \\
& +\xi_{5} u_{1} k_{2} x_{D}+\xi_{6} u_{1} k_{6} x_{G} \\
& \frac{d \xi_{2}}{d t}=-\xi_{1} u_{1} k_{1} x_{A}+\xi_{2} u_{1} k_{1} x_{A}-\xi_{3} u_{1} k_{1} x_{A} \\
& +\xi_{5} u_{1} k_{1} x_{A} \\
& \frac{d \xi_{3}}{d t}=\xi_{1}\left(u_{1} k_{2} x_{B}-u_{1} k_{3} x_{A}\right)-\xi_{2} u_{1} k_{2} x_{B} \\
& +\xi_{3}\left(u_{1} k_{2} x_{B}+u_{1} k_{3} x_{A}\right)-\xi_{4} u_{1} k_{3} x_{A}-\xi_{5}\left(u_{1} k_{2} x_{B}\right. \\
& \left.-u_{1} k_{3} x_{A}\right) \\
& \frac{d \xi_{4}}{d t}=-\xi_{1}\left(-u_{1} k_{4} x_{B}+u_{1} k_{5} x_{A}\right)-\xi_{3} u_{1} k_{4} x_{B} \\
& -\xi_{4}\left(-u_{1} k_{4} x_{B}-u_{1} k_{5} x_{A}\right)-\xi_{5} u_{1} k_{4} x_{B}-\xi_{6} u_{1} k_{5} x_{A} \\
& \frac{d \xi_{5}}{d t}=-\xi_{1}\left(u_{1} k_{1} x_{T}+u_{1} k_{3} x_{D}+u_{1} k_{5} x_{M}\right)+\xi_{2} u_{1} k_{1} x_{T} \\
& -\xi_{3}\left(u_{1} k_{1} x_{T}-u_{1} k_{3} x_{D}\right)-\xi_{4}\left(u_{1} k_{3} x_{D}-u_{1} k_{5} x_{M}\right) \\
& -\xi_{5}\left(-u_{1} k_{1} x_{T}-u_{1} k_{3} x_{D}-u_{1} k_{5} x_{M}\right)+\xi_{6} u_{1} k_{6} x_{B} \\
& \frac{d \xi_{6}}{d t}=\xi_{1} u_{1} k_{6} x_{B}-\xi_{4} u_{1} k_{6} x_{B}+\xi_{6} u_{1} k_{6} x_{B}
\end{aligned}
$$

along with the boundary conditions, $\xi_{i}\left(t_{f}\right)=0, i=1, \ldots, 6$. 
Proof. The Hamiltonian can be taken as:

$$
\begin{array}{r}
H=P u_{1}^{2}(t)+Q u_{2}^{2}(t)-R x_{B}^{2}(t)+\sum_{i=1}^{6} \xi_{i} f_{i}(x, T), \\
\quad i=1,2, \ldots, 6 .
\end{array}
$$

According to the Pontryagin Minimum Principle [33], the unconstrained optimal control pair $\left(u_{1}(t), u_{2}(t)\right)$ satisfies the following equation,

$$
\frac{\partial H}{\partial u_{i}^{*}}=0, \quad i=1,2 .
$$

Thus from (19), we have

$$
\begin{aligned}
& u_{1}^{*}(t)=\frac{-\sum_{i=1}^{6} \xi_{i} f_{i}(x, T)}{2 P}, \\
& u_{2}^{*}(t)=\frac{k_{S} x_{B}\left(1-x_{B} / B_{\max }\right)\left(-\xi_{1}\right)}{2 Q} .
\end{aligned}
$$

Due to the boundedness of the optimal control,

$$
\begin{aligned}
& u_{1}^{*}(t)=\max \left(0, \min \left(1, \frac{-\sum_{i=1}^{6} \xi_{i} f_{i}(x, T)}{2 P}\right)\right), \\
& u_{2}^{*}(t) \\
& \quad=\max \left(0, \min \left(1, \frac{k_{S} x_{B}\left(1-x_{B} / B_{\max }\right)\left(-\xi_{1}\right)}{2 Q}\right)\right) .
\end{aligned}
$$

According to Pontryagin Minimum Principle [29], the adjoint system can be obtained from the following equation [23],

$$
\frac{d \xi_{i}}{d t}=-\frac{\partial H}{\partial x_{i}}, \quad i=1,2,3,4,5,6
$$

where $x_{i} \equiv\left(x_{B}, x_{T}, x_{D}, x_{M}, x_{A}, x_{G}\right)$ and the necessary condition satisfying the optimal control pair $u^{*}(t)$ are

$$
\begin{aligned}
& H\left(x_{i}(t), u_{j}^{*}(t), \xi_{i}(t), t\right) \\
& =\min _{u_{j} \in U}\left(H\left(x_{i}(t), u_{j}(t), \xi_{i}(t), t\right)\right), \\
& \quad \text { where } i=1,2,3,4,5,6, j=1,2 .
\end{aligned}
$$

So, the adjoint system (17), corresponding to the system (10), can be obtained by (22). Boundary conditions for adjoint system $(17)$ are $\xi_{i}\left(t_{f}\right)=0(i=1, \ldots, 6)$ as the salvage function in the objective functional (equation (14)) is zero.

Now, the system (17) can be written in compact form as:

$$
\frac{d \xi_{i}}{d t}=F_{i}\left(x_{i}, \xi_{i}, t\right)
$$

where $F_{i}(i=1, \ldots, 6)$ are the right sides of system (17) and $x_{i}(i=1, \ldots, 6)$ are the state variables representing the concentration of each components $x_{B}, x_{T}, x_{D}, x_{M}, x_{A}$, and $x_{G}$ respectively and $\xi_{i}(i=1,2, \ldots, 6)$ are the adjoint variables.

Thus, (10), (17), and (21) represent the optimality system with $\xi_{i}\left(t_{f}\right)=0(i=1, \ldots, 6)$ as the boundary conditions. Also, $x_{B}(0)=0, x_{T}(0)=x_{T_{0}}, x_{D}(0)=0, x_{M}(0)=0, x_{A}(0)=$ $x_{A_{0}}, x_{G}(0)=0$ are treated as initial conditions. We solve state system (10) by forward integration and the adjoint system (17) by backward integration using a numerical method such as RK4 method.

The optimal profiles for temperature $\left(T^{*}\right)$ and stirring $\left(N^{*}\right)$ can be obtained by the following relations:

$$
\begin{aligned}
& u_{1}^{*} k_{i}=\alpha_{i} e^{-\beta_{i} / T^{*}}, \\
& u_{2}^{*} k_{s}=\frac{a}{1+\exp \left(-b\left(N^{*}-c\right)\right)} .
\end{aligned}
$$

4.2.1. Uniqueness of the Optimal Control Pair. In this section, we show that the control pair $\left(u_{1}, u_{2}\right)$ is unique for the system (10).

Let us suppose that, $\left(x_{1}, x_{2}, x_{3}, x_{4}, x_{5}, x_{6}, \xi_{1}, \xi_{2}, \xi_{3}, \xi_{4}\right.$, $\left.\xi_{5}, \xi_{6}\right)$ and $\left(\overline{x_{1}}, \overline{x_{2}}, \overline{x_{3}}, \overline{x_{4}}, \overline{x_{5}}, \overline{x_{6}}, \overline{\xi_{1}}, \overline{\xi_{2}}, \overline{\xi_{3}}, \overline{\xi_{4}}, \overline{\xi_{5}}, \overline{\xi_{6}}\right)$ are two solutions of the system (10) and (17).

Let us consider $x_{i}=e^{\lambda t} p_{i}$, and $\xi_{i}=e^{-\lambda t} q_{i}$, for $i=$ $1,2, \ldots, 6$.

Similarly, $\overline{x_{i}}=e^{\lambda t} \overline{p_{i}}$, and $\overline{\xi_{i}}=e^{-\lambda t} \overline{q_{i}}$, for $i=1,2, \ldots, 6$.

Then optimal controls parameter take the form,

$$
\begin{aligned}
& u_{1}=\max \left(0, \min \left(1, \frac{-\sum_{i=1}^{6} e^{-\lambda t} q_{i} f_{i}\left(e^{\lambda t} p_{i}, t\right)}{2 P}\right)\right), \\
& u_{2}=\max \left(0, \min \left(1, \frac{-k_{s} p_{i} q_{i}\left(1-e^{\lambda t} p_{i} / B_{\max }\right)}{2 Q}\right)\right), \\
& \overline{u_{1}}=\max \left(0, \min \left(1, \frac{-\sum_{i=1}^{6} e^{-\lambda t} \overline{q_{i}} f_{i}\left(e^{\lambda t} \overline{p_{i}}, t\right)}{2 P}\right)\right), \\
& \overline{u_{2}}=\max \left(0, \min \left(1, \frac{-k_{s} \overline{p_{i}} \overline{q_{i}}\left(1-e^{\lambda t} \overline{p_{i}} / B_{\max }\right.}{2 Q}\right)\right) .
\end{aligned}
$$

Thus, we have the following two inequalities,

$$
\begin{aligned}
& \int_{t_{i}}^{t_{f}}\left(u_{1}-\overline{u_{1}}\right)^{2} d t \leq \widetilde{C_{1}} \int_{t_{i}}^{t_{f}}\left[\sum_{i=1}^{6}\left|q_{i}-\overline{q_{i}}\right|^{2}\right] d t, \\
& \int_{t_{i}}^{t_{f}}\left(u_{2}-\overline{u_{2}}\right)^{2} d t \leq \widetilde{C_{2}} \int_{t_{i}}^{t_{f}}\left[\left|q_{i}-\overline{q_{i}}\right|^{2}\right] d t .
\end{aligned}
$$

Substituting $x_{i}=e^{\lambda t} p_{i}$, and $\xi_{i}=e^{-\lambda t} q_{i}$, (for $\left.i=1,2, \ldots, 6\right)$ in (11) and (19) we have,

$$
\begin{aligned}
& \dot{p}_{i}+\lambda p_{i}=e^{-\lambda t} f_{i}\left(e^{\lambda t} p_{i}, t\right), \quad i=1,2, \ldots, 6, \\
& \dot{q}_{i}-\lambda q_{i}=e^{\lambda t} F_{i}\left(e^{\lambda t} p_{i}, e^{-\lambda t} q_{i}, t\right) .
\end{aligned}
$$


$F_{i},(i=1,2, \ldots, 6)$ are given in $(25)$ and as for example, the differential equation for $i=2$,

$$
\begin{aligned}
\dot{p}_{2} & +\lambda p_{2}=e^{\lambda t}\left(-u_{1} k_{1} p_{2} p_{5}+u_{1} k_{2} p_{1} p_{3}\right) \\
\dot{q}_{2} & -\lambda q_{2}=e^{\lambda t}\left(-u_{1} k_{1} q_{1} p_{5}+u_{1} k_{1} q_{2} p_{5}-u_{1} k_{1} q_{3} p_{5}\right. \\
& \left.+k_{1} u_{1} q_{5} p_{5}\right) .
\end{aligned}
$$

We have another set of twelve such similar equations for the substitution $\overline{x_{i}}=e^{\lambda t} \overline{p_{i}}, \overline{\xi_{i}}=e^{-\lambda t} \overline{q_{i}}$, for $i=1,2, \ldots, 6$.

Here we subtract the equations for $\bar{x}_{i}$ from $x_{i}$, and $\bar{\xi}_{i}$ from $\xi_{i}$ for $i=1,2, \ldots, 6$. Next, each subtracted equation is multiplied by an appropriate function and then integrated from initial time $\left(t_{i}\right)$ to final time $\left(t_{f}\right)$.

Thus, we have the following inequalities,

$$
\begin{gathered}
\frac{1}{2}\left(p_{i}-\overline{p_{i}}\right)^{2}\left(t_{f}\right)+\lambda \int_{t_{i}}^{t_{f}}\left(p_{i}-\overline{p_{i}}\right)^{2} d t \\
\leq \widetilde{C_{3}} e^{\lambda t_{f}} \int_{t_{i}}^{t_{f}}\left[\sum_{i=1}^{6}\left|p_{i}-\overline{p_{i}}\right|^{2}\right] d t \\
+\widetilde{C_{4}} \int_{t_{i}}^{t_{f}}\left[\sum_{i=1}^{6}\left|q_{i}-\overline{q_{i}}\right|^{2}\right] d t \\
\frac{1}{2}\left(q_{i}-\overline{q_{i}}\right)^{2}\left(t_{i}\right)+\lambda \int_{t_{i}}^{t_{f}}\left(q_{i}-\overline{q_{i}}\right)^{2} d t \\
\leq \widetilde{C_{5}} e^{\lambda t_{f}} \int_{t_{i}}^{t_{f}}\left[\sum_{i=1}^{6}\left|q_{i}-\overline{q_{i}}\right|^{2}\right] d t .
\end{gathered}
$$

Here, the constants $\widetilde{C_{1}}$ to $\widetilde{C_{5}}$ depend on the coefficients and the bounds on states and adjoints.

The above twelve inequalities are added and estimated to obtain the following result,

$$
\begin{gathered}
\frac{1}{2}\left[\sum_{i=1}^{6}\left(p_{i}-\overline{p_{i}}\right)^{2}\left(t_{f}\right)+\sum_{i=1}^{6}\left(q_{i}-\overline{q_{i}}\right)^{2}\left(t_{i}\right)\right] \\
+\lambda \int_{t_{i}}^{t_{f}}\left[\sum_{i=1}^{6}\left(p_{i}-\overline{p_{i}}\right)^{2}+\sum_{i=1}^{6}\left(q_{i}-\overline{q_{i}}\right)^{2}\right] d t \\
\leq\left(\widetilde{C_{6}}+\widetilde{C_{7}} e^{2 \lambda t_{f}}\right) \\
\cdot \int_{t_{i}}^{t_{f}}\left[\sum_{i=1}^{6}\left(p_{i}-\overline{p_{i}}\right)^{2}+\sum_{i=1}^{6}\left(q_{i}-\overline{q_{i}}\right)^{2}\right] d t,
\end{gathered}
$$

where $\widetilde{C_{6}}$ and $\widetilde{C_{7}}$ depend on the coefficients and the bounds of $p_{i}$, and $q_{i}, i=1,2, \ldots, 6$.

From the above relations we have,

$$
\begin{aligned}
& \left(\lambda-\widetilde{C_{6}}-\widetilde{C_{7}} e^{\lambda t_{f}}\right) \\
& \cdot \int_{t_{i}}^{t_{f}}\left[\sum_{i=1}^{6}\left(p_{i}-\overline{p_{i}}\right)^{2}+\sum_{i=1}^{6}\left(q_{i}-\overline{q_{i}}\right)^{2}\right] d t \leq 0 .
\end{aligned}
$$

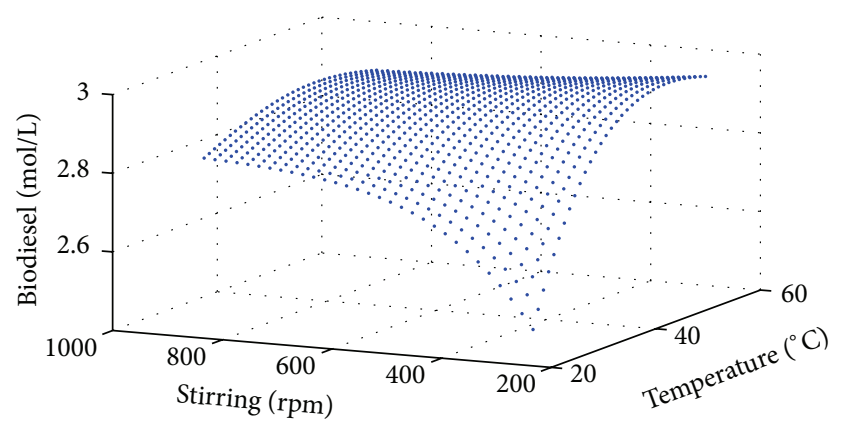

FIGURE 1: Final concentration of biodiesel is plotted as a function of temperature and stirrer speed with parameters as given in Table 1.

If we choose $\lambda$ such that $\lambda>\widetilde{C_{6}}+\widetilde{C_{7}}$ and $t_{f}<(1 / \lambda) \ln ((\lambda-$ $\left.\widetilde{C_{6}}\right) / \widetilde{C_{7}}$ ), then $p_{1}=\overline{p_{1}}, p_{2}=\overline{p_{2}}, p_{3}=\overline{p_{3}}, p_{4}=\overline{p_{4}}, p_{5}=\overline{p_{5}}$, $p_{6}=\overline{p_{6}}, q_{1}=\overline{q_{1}}, q_{2}=\overline{q_{2}}, q_{3}=\overline{q_{3}}, q_{4}=\overline{q_{4}}, q_{5}=\overline{q_{5}}$, and $q_{6}=\overline{q_{6}}$.

Hence, the solution is unique in the time interval $\left[t_{i}, t_{f}\right]$ and also the control pair is unique for the optimality of the system (10) which minimizes the objective functional $J$.

\section{Numerical Simulation}

In previous section, Pontryagin Minimum Principle is used to observe the effect of optimal control in the system dynamics with the help of Hamiltonian. In this section, the model equation (6) and optimal control problem ((10) and (17)) are solved numerically using Matlab and the results are plotted in figures. The aim is to understand the effect of temperature and stirring on biodiesel yield in transesterification process.

Simultaneous effect of temperature and stirring can be seen in Figure 1. In this figure, final concentration of biodiesel is plotted as function of temperature $(T)$ and stirring $(N)$. It is revealed from this figure that, as stirring increases, biodiesel production also increases, because at higher mixing intensity the mass transfer resistance decreases.

It is also noticed from Figure 1 that both the reaction rate and mass transfer rate vary with changes in temperature and stirring. But the change of mass transfer rate with the change of temperature will be negligible compared to the effect of temperature change on reaction rate. As reaction temperature increases, yield of biodiesel is also increased. But after a certain level of temperature (above $50^{\circ} \mathrm{C}$ ), biodiesel yield is decreased. Temperature above $60^{\circ} \mathrm{C}$ should be avoided because at the high temperature, alcohol vaporizes which ultimately changes optimum molar ratio of alcohol and triglycerides or may be due to saponification reaction $[26,34$, 35].

Thus, as a combined parameter, mixing intensity and temperature have major influence on mass transfer which ultimately increases the yield of biodiesel. Now, applying optimal controlling on stirring speed, along with temperature during the reaction process, it has significant impact for optimizing the biodiesel production. Figure 2 shows the optimal profiles of stirring $\left(N^{*}\right)$ and temperature $\left(T^{*}\right)$. This result shows that initially higher mechanical stirring is needed 

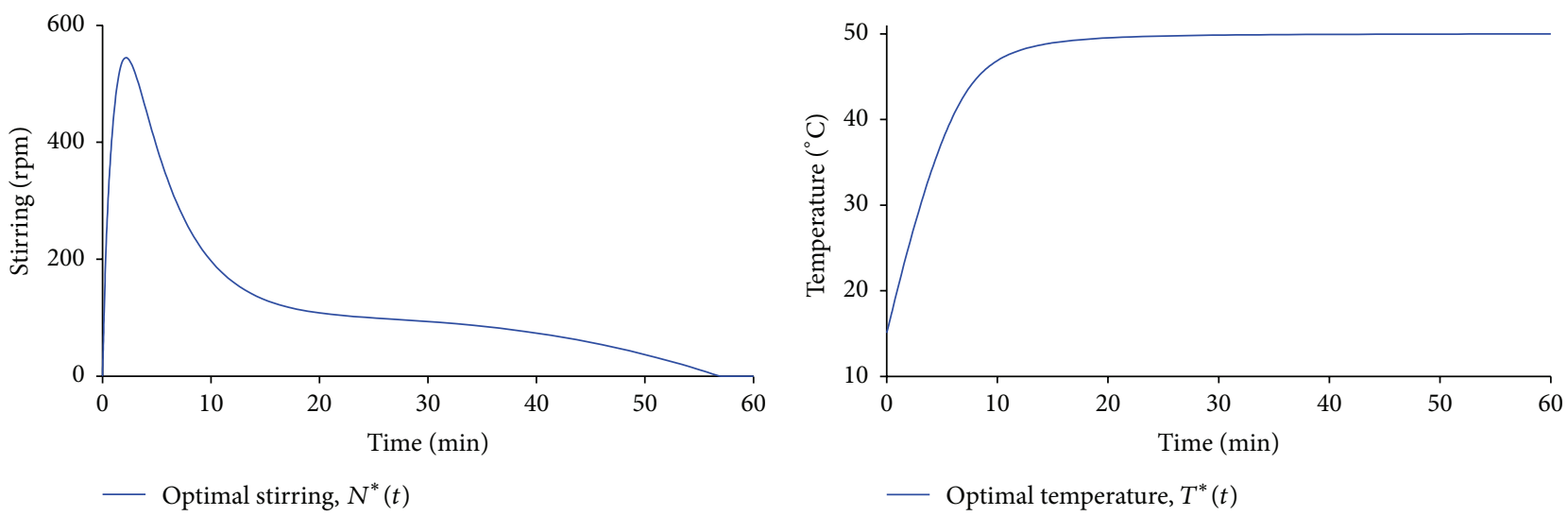

FIGURE 2: Optimal temperature and optimal stirring profiles are plotted as a function of time with $x_{T}(0)=1 \mathrm{~mol} / \mathrm{L}, x_{A}(0)=6 \mathrm{~mol} / \mathrm{L}$, and other parameters as in Table 1.

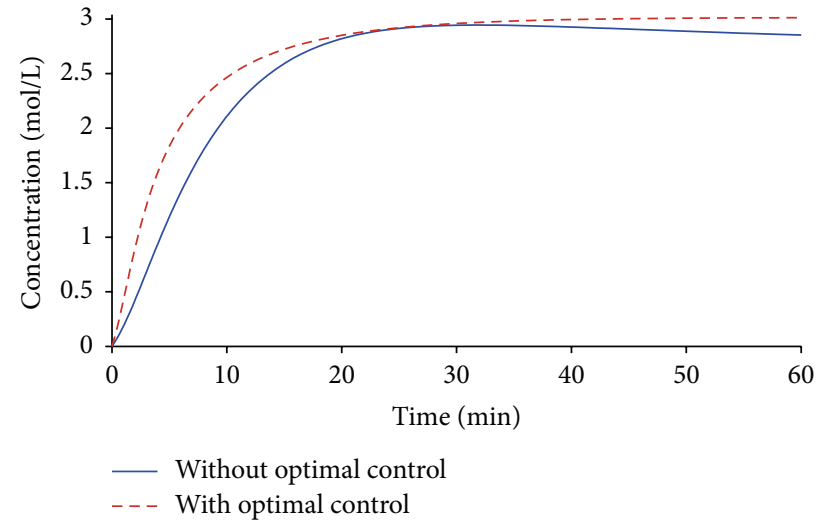

Figure 3: Concentration of biodiesel is plotted as a function of time for two cases: case I: with optimal temperature $\left(T^{*}(t)\right)$ and optimal stirring $\left(N^{*}\right)$ and case II: with fixed temperature $\left(50^{\circ} \mathrm{C}\right)$ and fixed stirring $(600 \mathrm{rpm})$.

for transesterification reaction to minimize mass transfer resistance and to increase reaction rate. Thus, increasing the rate of mixing intensity is essential from the beginning of the reaction. After 10 minutes of reaction (evident from Figure 2), a lesser stirring (below $100 \mathrm{rpm}$ ) but high temperature $\left(\right.$ about $\left.50^{\circ} \mathrm{C}\right)$ is required at this stage; that is, temperature is the main factor which controls the reaction system after 10 minutes of reaction.

Figure 3 illustrates the concentration profiles of biodiesel for two cases, case I: with optimal control pair and case II: without optimal control. In this figure, the effect of optimal control pair is reflected on the concentration of biodiesel. In case I, the concentration of biodiesel at optimal condition reaches its maximum value, $3 \mathrm{~mol} / \mathrm{L}$, while in case II the maximum concentration is $2.854 \mathrm{~mol} / \mathrm{L}$ after 60 minutes.

\section{Discussion and Conclusion}

In an earlier study, Roy et al. [17] have considered a system of biodiesel production and evaluated the effect of mass transfer, in terms of stirring, by developing a mathematical model. Also, an optimal profile of stirring was determined, at constant temperature, for which maximum biodiesel could be obtained. Basir and Roy [23] have applied control on temperature to maximize the yield of biodiesel giving a fixed stirring to the system. optimal temperature profile was also determined for maximum biodiesel production. In the present work the novelty belongs in the intuitive quality enhancement by varying both the temperature and stirring speed to optimize biodiesel yield. Combined effect of temperature and stirring on biodiesel productivity has been shown. Further, optimal profiles of temperature and stirring are determined, analytically as well as numerically, for which maximum yield of biodiesel can be obtained. It is also shown that the optimal control pair (temperature and stirring) has a significant impact on mass transfer resistance. Moreover, it has been shown analytically that this control pair is unique for the optimality of the system.

We may conclude that maximum biodiesel production can be obtained by minimizing mass transfer resistance and it can be done by introducing control on temperature and stirring simultaneously. This paper thus provides an idea of describing the simultaneous effect of temperature and stirring on the mass transfer for faster rate of biodiesel production.

\section{Conflict of Interests}

The authors declare that there is no conflict of interests regarding the publication of this paper.

\section{Acknowledgments}

It is a pleasure to acknowledge the learned reviewers for their constructive and insightful comments, which helped us to improve the quality of this work, and Dr. Joydeep Pal, Department of Mathematics, Jadavpur University, Kolkata, India, for language revision. Research is supported by UGC major research project, F. no. 41-768/2012(SR), dated 18 July 2012. 


\section{References}

[1] K. M. Rahman, M. Mashud, M. Roknuzzaman, and A. Al Galib, "Biodiesel from jatropha oil as an alternative fuel for diesel engine," International Journal of Mechanical and Mechanics Engineering, vol. 10, no. 3, pp. 1-6, 2010.

[2] G. B. Adebayo, O. M. Ameen, and L. T. MAbaas, "Physicochemical properties of biodiesel produced from Jatropha curcas oil and fossil diesel," Journal of Microbiology and Biotechnology Research, vol. 1, no. 1, pp. 12-16, 2011.

[3] H. S. Ginwal, P. S. Rawat, and R. L. Srivastava, "Seed source variation in growth performance and oil yield of Jatropha curcas Linn. in central India," Silvae Genetica, vol. 53, no. 4, pp. 186192, 2004.

[4] F. Al Basir, S. Datta, and P. K. Roy, "Studies on biodiesel production from Jatropha curcas oil using chemical and biochemical methods - a mathematical approach," Fuel, vol. 158, pp. 503-511, 2015.

[5] H. J. Berchmans, K. Morishita, and T. Takarada, "Kinetic study of hydroxide-catalyzed methanolysis of Jatropha curcas-waste food oil mixture for biodiesel production," Fuel, vol. 104, pp. 4652, 2013.

[6] F. Ataya, M. A. Dubé, and M. Ternan, "Acid-catalyzed transesterification of canola oil to biodiesel under single and two-phase reaction conditions," Energy and Fuels, vol. 21, no. 4, pp. 24502459, 2007.

[7] F. Ma, L. D. Clements, and M. A. Hanna, "The effect of mixing on transesterification of beef tallow," Bioresource Technology, vol. 69, no. 3, pp. 289-293, 1999.

[8] F. A. Basir and P. K. Roy, "Production of biodiesel using enzymatic transesterification of Jatropha curcas oil: a mathematical study," Mathematics in Engineering, Science and Aerospace, vol. 5, no. 2, pp. 175-184, 2014.

[9] A. Srivastava and R. Prasad, "Triglycerides-based diesel fuels," Renewable and Sustainable Energy Reviews, vol. 4, no. 2, pp. 111$133,2000$.

[10] Y. Zhang, M. A. Dubé, D. D. McLean, and M. Kates, “Biodiesel production from waste cooking oil: 1 . Process design and technological assessment," Bioresource Technology, vol. 89, no. 1, pp. 1-16, 2003.

[11] B. Freedman, R. O. Butterfield, and E. H. Pryde, "Transesterification kinetics of soybean oil 1," Journal of the American Oil Chemists' Society, vol. 63, no. 10, pp. 1375-1380, 1986.

[12] M. E. Bambase Jr., N. Nakamura, J. Tanaka, and M. Matsumura, "Kinetics of hydroxide-catalyzed methanolysis of crude sunflower oil for the production of fuel-grade methyl esters," Journal of Chemical Technology and Biotechnology, vol. 82, no. 3, pp. 273-280, 2007.

[13] L. C. Meher, D. Vidya Sagar, and S. N. Naik, "Technical aspects of biodiesel production by transesterification-a review," Renewable and Sustainable Energy Reviews, vol. 10, no. 3, pp. 248-268, 2006.

[14] H. J. Berchmans, K. Morishita, and T. Takarada, "Kinetic study of hydroxide-catalyzed methanolysis of Jatropha curcas-waste food oil mixture for biodiesel production," Fuel, vol. 104, pp. 4652, 2013.

[15] B. Freedman, E. H. Pryde, and T. L. Mounts, "Variables affecting the yields of fatty esters from transesterified vegetable oils," Journal of the American Oil Chemists Society, vol. 61, no. 10, pp. 1638-1643, 1984.
[16] A. V. Marjanović, O. S. Stamenković, Z. B. Todorović, M. L. Lazić, and V. B. Veljković, "Kinetics of the base-catalyzed sunflower oil ethanolysis," Fuel, vol. 89, no. 3, pp. 665-671, 2010.

[17] P. K. Roy, S. Datta, S. Nandi, and F. A. Basir, "Effect of mass transfer kinetics for maximum production of biodiesel from Jatropha curcas oil: a mathematical approach," Fuel, vol. 134, pp. 39-44, 2014.

[18] H. Noureddini and D. Zhu, "Kinetics of transesterification of soybean oil," Journal of the American Oil Chemists' Society, vol. 74, no. 11, pp. 1457-1463, 1997.

[19] X. L. Hou, Y. Q. Qi, X. G. Qiao, G. F. Wang, Z. F. Qin, and J. G. Wang, "Lewis acid-catalyzed transesterification and esterification of high free fatty acid oil in subcritical methanol," Korean Journal of Chemical Engineering, vol. 24, no. 2, pp. 311313, 2007.

[20] C. L. Peterson, D. L. Reece, R. Cruz, and J. Thompson, "A comparison of ethyl and methyl esters of vegetable oil as diesel fuel substitute," in Proceedings of the Alternative Energy Conference of ASAE, pp. 99-110, Nashville, Tenn, USA, December 1992.

[21] U. Rashid, F. Anwar, and G. Knothe, "Evaluation of biodiesel obtained from cottonseed oil," Fuel Processing Technology, vol. 90, no. 9, pp. 1157-1163, 2009.

[22] Y. C. Sharma, B. Singh, and J. Korstad, "High yield and conversion of biodiesel from a nonedible feedstock (Pongamia pinnata)," Journal of Agricultural and Food Chemistry, vol. 58, no. 1, pp. 242-247, 2010.

[23] F. A. Basir and P. K. Roy, "Optimal control on temperature to maximize biodiesel production from Jatropha curcas oil: a mathematical approach," International Journal of Biomathematics and Systems Biology, vol. 1, no. 1, 2014.

[24] G. Vicente, M. Martínez, and J. Aracil, "Kinetics of Brassica carinata oil methanolysis," Energy and Fuels, vol. 20, no. 4, pp. $1722-1726,2006$

[25] A. P. Vyas, J. L. Verma, and N. Subrahmanyam, "Effects of molar ratio, alkali catalyst concentration and temperature on transesterification of jatropha oil with methanol under ultrasonic irradiation," Advances in Chemical Engineering and Science, vol. 1, no. 2, pp. 45-50, 2011.

[26] U. Diwekar and P. T. Benavides, "Optimal control of biodiesel production in a batch reactor part I: deterministic control," Fuel, vol. 94, pp. 211-217, 2012.

[27] O. S. Stamenković, Z. B. Todorović, M. L. Lazić, V. B. Veljković, and D. U. Skala, "Kinetics of sunflower oil methanolysis at low temperatures," Bioresource Technology, vol. 99, no. 5, pp. 1131$1140,2008$.

[28] G. Brikhoff and G. C. Rota, Ordinary Differential Equations, Ginn, Boston, Mass, USA, 1982.

[29] R. V. Culshaw, S. Ruan, and R. J. Spiteri, "Optimal HIV treatment by maximising immune response," Journal of Mathematical Biology, vol. 48, no. 5, pp. 545-562, 2004.

[30] L. S. Pontryagin, V. G. Boltyanskii, R. V. Gamkarelidze, and E. F. Mishchenko, Mathematical Theory of Optimal Process, vol. 4, Gordon and Breach Science Publishers, 1986.

[31] W. H. Fleming and R. W. Rishel, Deterministic and Stochastic Optimal Control, Springer-Verlag, New York, NY, USA, 1975.

[32] D. L. Lukes, Differential Equations: Classical to Controlled, vol. 162 of Mathematics in Science and Engineering, Academic Press, New York, NY, USA, 1982.

[33] L. S. Pontryagin, V. G. Boltyanskii, R. V. Gamkrelidze, and E. F. Mishchenko, The Mathematical Theory of Optimal Processes, Interscience, 1962 (Russian). 
[34] E. M. Odin, P. K. Onoja, and A. U. Ochala, "Effect of process variables on biodiesel production via transesterification of Quassia undulata seed oil, using homogeneous catalyst," International Journal of Scientific \& Technology Research, vol. 2, no. 9, pp. 267-276, 2013.

[35] D. Y. C. Leung and Y. Guo, "Transesterification of neat and used frying oil: optimization for biodiesel production," Fuel Processing Technology, vol. 87, no. 10, pp. 883-890, 2006. 


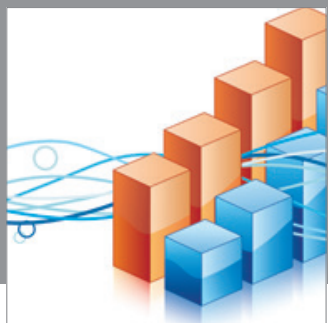

Advances in

Operations Research

mansans

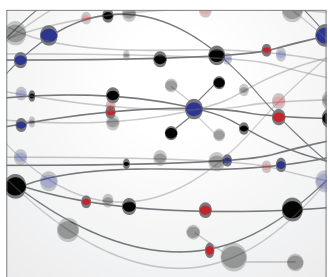

The Scientific World Journal
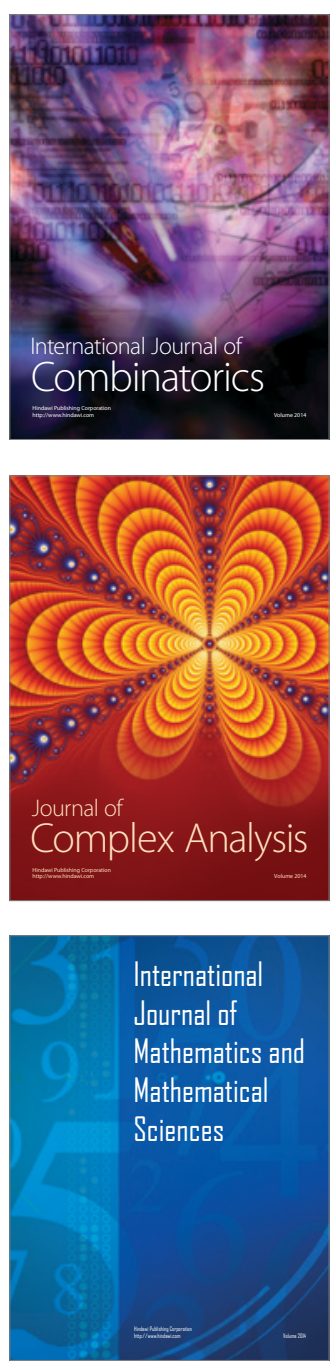
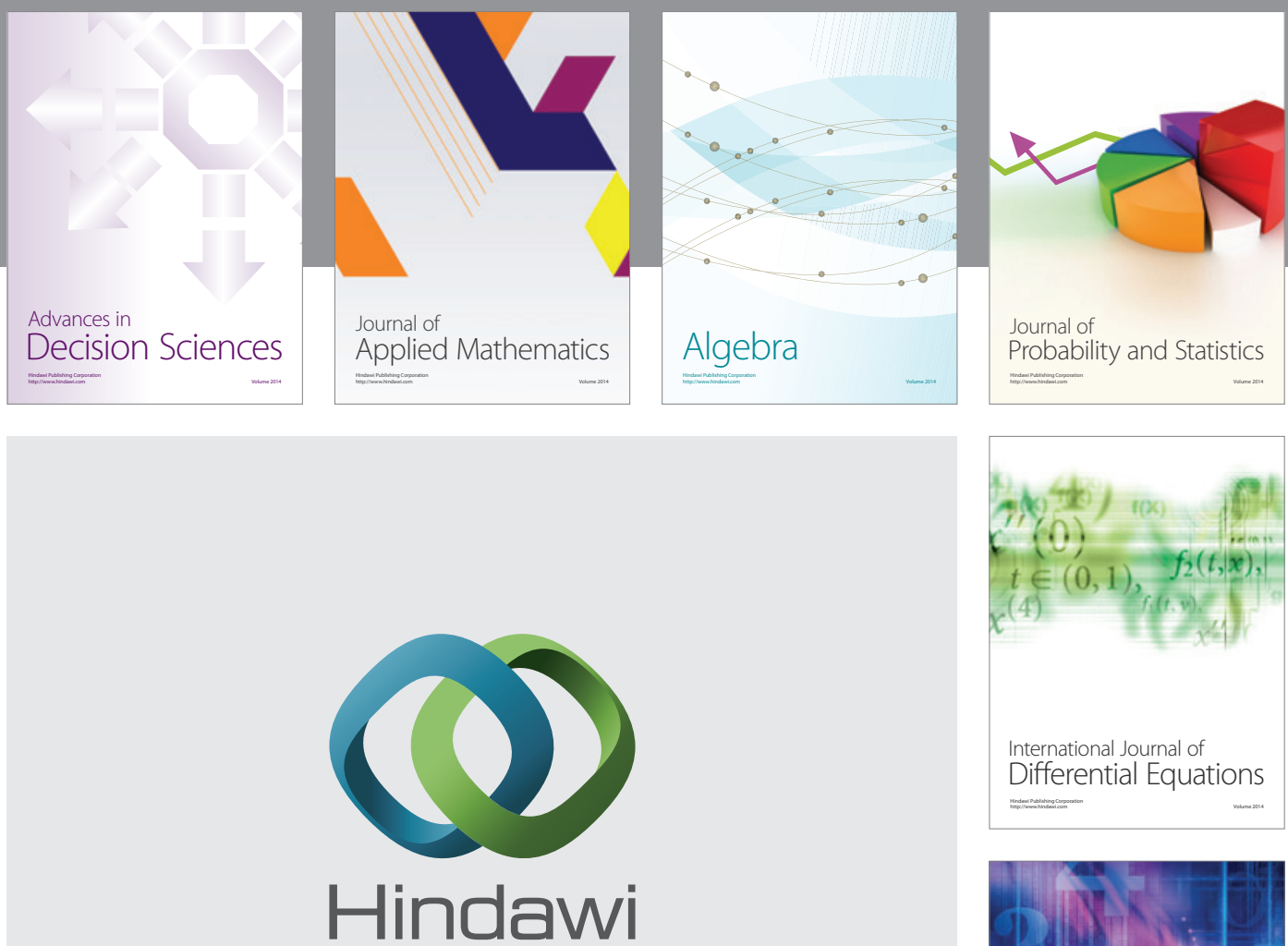

Submit your manuscripts at http://www.hindawi.com
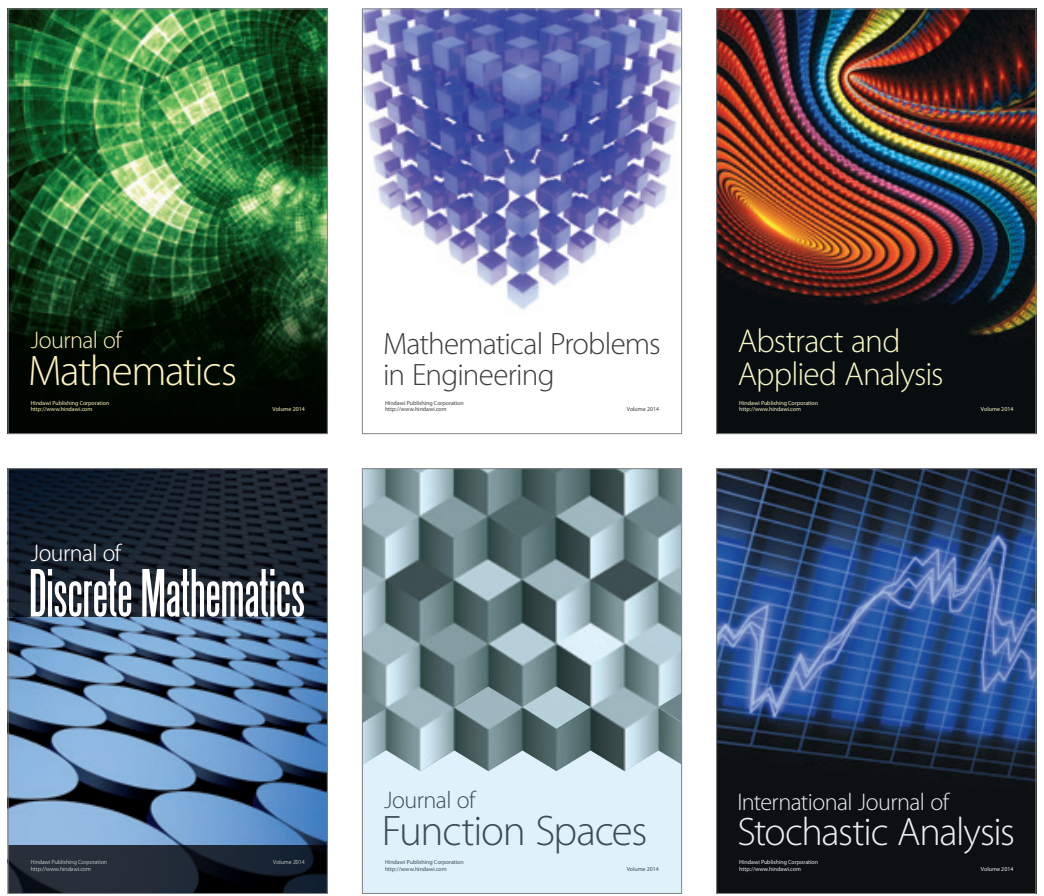

Journal of

Function Spaces

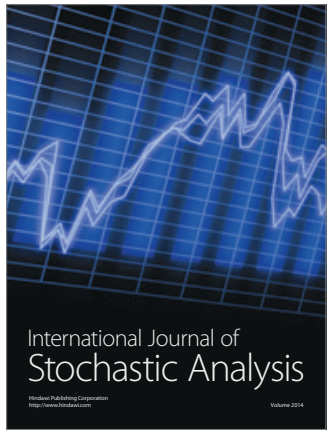

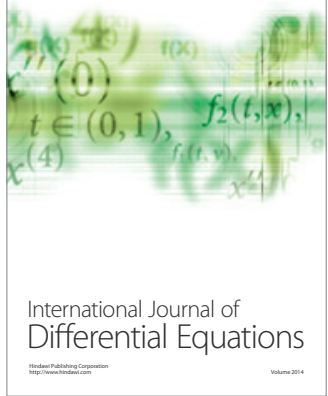
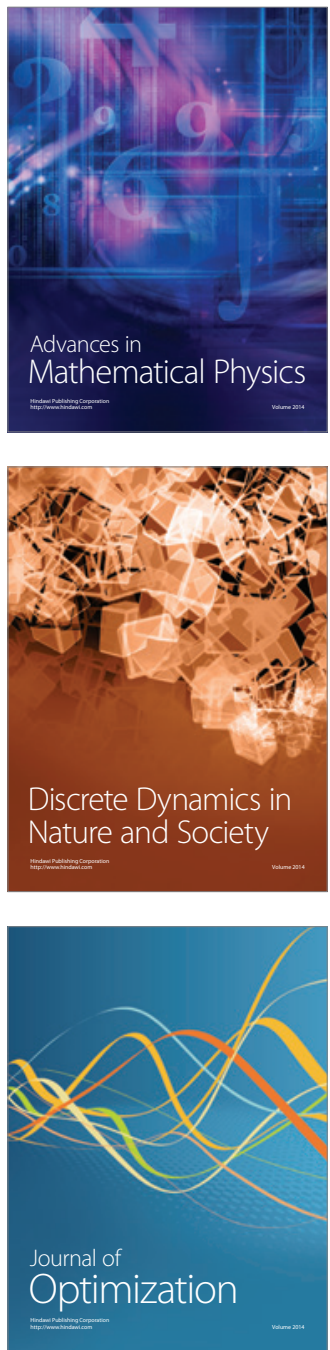